\title{
Correction to: Toward an Ethics of Interactive Storytelling at Dark Tourism Sites in Virtual Reality
}

Joshua A. Fisher and Sarah Schoemann

Correction to:

Chapter "Toward an Ethics of Interactive Storytelling at Dark Tourism Sites in Virtual Reality" in: R. Rouse et al. (Eds.): Interactive Storytelling, LNCS 11318, https://doi.org/10.1007/978-3-030-04028-4_68

In the original version of this chapter the given name of the second author was misspelled. It has been corrected. 